\title{
STRATEGIES OF DELAY DELIVERY AND CONTROLLABLE LEAD TIME TO OPTIMIZE THE TOTAL COST IN SUPPLY CHAIN CONSIGNMENT INVENTORY
}

\author{
Chidurala Srinivas \\ Professor, Mechanical Engineering Department \\ Vaageswari College of Engineering \\ Karimnagar, Telangana State, India.
}

\begin{abstract}
This paper describes about two strategies in consignment inventory based supply chain with controllable lead time and delaying last delivery comprising a two level supply chain involving single vendor and multi buyers. This model would give minimum joint total expected cost of the strategies involving vendor and buyer, simultaneously to optimize quantitative decision variables. Numerical examples are presented to demonstrate the benefit of the proposed strategies and the effect of changes on the cost and parameters are studied.
\end{abstract}

Key words: consignment inventory; supply chain; joint total expected cost; delay delivery; controllable lead time; crashing cost.

Cite this Article: Chidurala Srinivas, Strategies of Delay Delivery and Controllable Lead Time to Optimize the Total Cost in Supply Chain Consignment Inventory, International Journal of Production Technology and Management (IJPTM), 10(1), 2019, pp. 9-18.

http://iaeme.com/Home/issue/IJPTM?Volume=10\&Issue=1

\section{INTRODUCTION}

The global competitive and technology has brought a big challenge to the enterprises to meet the customer needs in the way of service and acceptable costs. In order to fulfil the customer needs, the entrepreneurs have to see the network optimization to customer mode network business models with the aim of minimizing cost and maximizing service without compromising the quality of customer need end product. Since the inventories can cost approximately between 8 to 20 percentage of total product value, hence an effective controlling of inventory is critical and most essential. The new demand pointed towards reduction in product total manufacturing cost, which in turn pointed towards their suppliers and this formed a chain reaction. Eventually in this aspect inventory is one of the most widely discussed area to improve efficiency. Hence the vendor plays a key role in the maintain the inventory. Since 
1980, the popularity of Vendor Managed Inventory (VMI) has grown with the introduction of this concept in Wal-Mart, Procter \& Gamble, and later initiated by other companies including Campbell Soup, Johnson \& Johnson and by European firms.

To reduce inventory cost in business, Supply Chain (SC) has become a suitable tool. Supply chain is the process of planning, implementing, and controlling the activities as efficiently as possible. From the manufacturing perspective, supply chain echelon consists of storing raw materials, work-in-process inventory, and finished goods from point-of-origin to point-ofconsumption. Hence, inventory plays a key role along the supply chain echelons.

Houlihan [1] credited for being first to coining the term of Supply Chain (SC) with concepts and viewing it as a new strategy for global competitive business decisions. Many definitions of $\mathrm{SC}$ have been mentioned in the literature and in practice, although the underlying philosophy is the same. Simchi-Levi et al. [2] defined Supply Chain as unique approach utilized to efficiently integrate the various echelons such as suppliers, manufacturers, warehouse and stores, so that merchandise is produced and distributed at the right quantities, to the right location and at the required time in order to minimize echelon cost, while satisfying service level requirements. However, most of the quantitative models in supply chain issues is dominated by the framework of multi-echelon serial systems where, a relationship in between a single vendor and multi buyers are to be considered.

Consignment Inventory (CI) is one of the most effective approach in the supply chain echelon inventory control strategy. Because, the approach leads to reduction of vendor inventory which uses the buyer warehouse to stock the finished products. In consignment inventory, the payments for supplier inventory is not released until goods have been sold at the consumer place.

The vendor managed inventory with consignment inventory arrangement is one of the policy that has been observed in the automotive industry. It is the work of Valentini and Zavanella [3] which has provided a primitive foundation for most of the later work related to this policy. The numerical model of Braglia and Zavanella [4] will be considered as the base model. Moreover, Braglia and Zavanella [4] provided a comparison with the classical model of Hill $[5,6]$.

Srinivas and Rao $[7,8,9,10]$ had classified the Consignment Inventory strategy into four different models such as;

1). Basic Consignment Inventory model,

2). Consignment Inventory model with delay delivery,

3). Consignment Inventory model with Information sharing, and with delay delivery, and

4). Consignment inventory with controllable lead time strategy. They concluded that the CI policy implementation could be advantageous.

This paper is structured in to four sections: Introduction in section I, section II describes the Consignment inventory strategy with delay delivery and controllable lead time, section III illustrative examples, IV typical results and conclusions.

\section{CONSIGNMENT INVENOTY STRATEGIES}

In this paper among four CI models which has mentioned in Srinivas and Rao [7,8,9,10], the author have discussed and made a comparative analysis using numerical examples of two most important strategies of consignment inventory namely delay delivery and controllable lead times with single vendor - multi buyer model in SC which is viewed as a classification of divergent SC with end to multi ends case. The significance of production to demand ratio is also discussed along with other variables. 


\section{Notations used are summerized below}

$h_{v} \quad$ vendor stock holding cost/unit/unit time

$h_{b} \quad$ buyer stock holding cost/unit/unit time

Av batch set-up cost (vendor)

$\mathrm{Ab}$ order emission cost (buyer)

$\mathrm{p} \quad$ vendor manufacture rate (continuous)

D product demand units/ time seen by the buyer (continuous)

$\mathrm{T}_{\mathrm{C}}$ average total costs of the system / time

$\sigma \quad$ standard deviation of customer demand / time

$\pi \quad$ buyer back order cost

$\mathrm{Li}$ lead-time length for the buyer

$\mathrm{C}_{\mathrm{L}} \quad$ lead time crashing cost / cycle normal probability density function

$\Phi \quad$ cumulative probability density function

$\mathrm{n}$ number of shipments /production batch

y buyer range

z safety factor

c cycle time

\section{The following assumptions are used}

- one setup of continuous review inventory replenishment system for an infinite horizon of single vendor - multiple buyer

- buyer and vendor holding cost is independent of items transported but proportional to its holding of stock time

- customer demand rate and the delivery lead time for each buyer are continuous with known, stationary probability distributions, where as demand is normally distributed

- shortages may be allowed

- $\quad \sum_{i=1}^{y} D_{i}<$ production rate $\ngtr$ production capacity

- $\frac{p}{n_{i}} \geq \sum \frac{D_{i}}{n_{i}}$ and $n_{i} \geq 1 \forall b_{i}$

- $\quad C I-k^{l} \forall k^{l}<n$

\section{Consignment inventory with delay delivery $\left(C I-k^{1}\right)$}

In consignment inventory strategy, the maximum level of buyer's inventory may reach at any instance during cycle time. One solution offered by Braglia and Zavanella [4] is to delaying the last delivery to buyer. The principle assumption is that the delayed delivery is retained by vendor until buyer is ready to take the last shipment. This assumption is reasonable approximation to reality when there is no information sharing between vendor and buyer. Hence it doesn't allow exceeding the maximum limit ' $S$ ' in the buyer's inventory. In this situation, the shipments if any with vendor must wait at vendor's place. Braglia and Zavanella [4] has consider the consignment inventory only for single vendor single buyer. Whereas, in this work it has been extended to single vendor multiple buyers.

\section{Consignment inventory with delay delivery model formulation}

The joint total expected cost $=$ vendor set up cost + vendor holding cost + buyer ordering cost

+ buyer holding cost + shortage cost 


$$
\begin{aligned}
& T_{C}^{C L-k^{k}}=\frac{A_{v}+\sum_{i=1}^{y}\left(n_{i} A_{b i}\right)}{c}+h_{v} c\left\{\frac{1}{2 p}\left[\sum_{i=1}^{y} \frac{D_{i}^{2}}{n_{i}}\right]+\sum_{i=1}^{y}\left(\frac{D_{i}}{n_{i}} \frac{\left(p-D_{i}\right)}{n_{i} p} \frac{\left(k_{i}^{1}+1\right)}{2} k_{i}^{1}\right)\right\} \\
& +\sum_{i=1}^{y}\left\{\frac{h_{b i}}{2}\left\{\left(n_{i}-k_{i}^{1}\right) q_{i}-\left(n_{i}-k_{i}^{1}-1\right) D_{i}\left[\frac{D_{i} c}{n_{i} p}+\sum_{j \neq i}\left(\frac{D_{j} c}{n_{i} p}\right)\right]\right\}\right\} \\
& +\sum_{i=1}^{y}\left(h_{b i} z \sigma_{i} \sqrt{L_{i}}\right)+\frac{\sum_{i=1}^{y}\left(\pi \sigma \psi(z) \sqrt{L_{i}}\right)}{c}
\end{aligned}
$$

\section{Iterative analysis used in CI-k}

step 1: set $n_{i}=1$;

step 2: set $n_{i+1}=n_{i}+1$;

step 3: set $k_{i}^{1}=1$;

step 4: compute JTEC $\left(c, n_{i}, k_{i}^{1}, z\right)$;

if $\operatorname{JTEC}\left(c_{i}^{*}, n_{i}^{*}, k_{i}^{1^{*}}, z_{i}^{*}\right) \leq \operatorname{JTEC}\left(c_{n_{i}-1}^{*}, n_{i\left(n_{i}-1\right)}, k_{i\left(n_{i}-1\right)}^{1^{*}}, z_{(n i-1)}^{*}\right)$

step 5: then $\left(c_{i}^{*}, n_{i}^{*}, k_{i}^{1^{*}}, z_{i}^{*}\right)$ are the optimal parameters and the minimum joint total expected cost $\operatorname{JTEC}\left(c_{i}^{*}, n_{i}^{*}, k_{i}^{k^{*}}, z^{*}\right)$

\section{Consignment inventory with controallable lead time}

This model is used a newly developed concept, the buyer will negotiate with vendor to reduce the lead time as much as it can be possible to a point where it is acceptable to the vendor without disturbing stable production and delivery schedule. The inventory level is reviewed continuously and if any shortages exists may be allowed with fully backordered. It has to be noted that the delivery lead time is null, however the batch is to be manufactured, so as to there exists a system lead time other than zero. With this by adding an additional cost, the system lead time can be controlled. Thus, the lead time is reduced one at a time starting from first independent component because it having minimum unit crashing cost per unit time, and then the second independent component, and so on. When the lead time is reduced/controlled, its correspond handling cost for that unit time is also reduced, but the crashing cost is added to total cost of buyer. The total length of system lead time which ensures the order transit even though lead time is crashed and shortages if any are permitted. Since lead time is a decision variable in this model, the extra costs incurred by the vendor will be fully transferred to the buyer if shortened lead time is requested may be considered as an investment in the business.

\section{Consignment inventory with controallable lead time model formulation}

Li will be the lead time with components $1,2,3 \ldots$ i which is to be crashed to minimum duration, and the $\mathrm{i}^{\text {th }}$ component has a normal duration 'bi' and minimum duration 'ai' and the controllable lead time crashing cost per unit time is ' $\mathrm{Ci}$ '; such that $\mathrm{C}_{1} \leq \mathrm{C}_{2} \leq \ldots \leq \mathrm{Cn}$., then $\mathrm{Li}$ is expressed as,

$$
L_{i}=L_{o}-\sum_{j=1}^{i-1} C_{j}\left(b_{j}-a_{j}\right)
$$

let $\quad L_{0}=\sum_{i=1}^{n} b_{j}$

then, $L_{i}=\sum_{j=1}^{n} b_{j}-\sum_{j-1}^{i-1} C_{j}\left(b_{j}-a_{j}\right)$ 
Strategies of Delay Delivery and Controllable Lead Time to Optimize the Total Cost in Supply Chain Consignment Inventory

the lead time crashing cost per cycle $\mathrm{C}_{\mathrm{L}}$ is given by

$$
C_{L}=C_{i}\left(L_{j-1}-L\right)+\sum_{j-1}^{i-1} C_{j}\left(b_{j}-a_{j}\right) \in C_{L}=0 \rightarrow L_{0}, \forall L \in\left[L_{i} L_{i-1}\right]
$$

Joint total expected cost for CI-LT model,

JTEC $=$ vendor set up cost + vendor holding cost + buyer ordering cost + buyer holding cost + shortage cost + lead time controllable crashing cost

$$
\begin{aligned}
T_{C}^{C I-L T} & =\frac{A_{v}+\sum_{i=1}^{v} n_{i} A_{b i}}{c}+h_{v} \frac{c}{2 p}\left[\sum_{i=1}^{y} \frac{D_{i}^{2}}{n_{i}}\right] \\
& +\sum_{i=1}^{v}\left\{\frac{h_{b i}}{2}\left\{D_{i} c-\left(n_{i}-1\right) D_{i}\left[\frac{D_{i} c}{n_{i} p}+\sum_{i \neq j} \frac{D_{j} c}{n_{i} p}\right]\right\}\right\} \\
& +\sum_{i=1}^{v}\left(h_{b i} z \sigma_{i} \sqrt{L_{i}}\right)+\frac{\sum_{i=1}^{v}\left(\pi_{i} \sigma_{i} \psi(z) \sqrt{L_{i}}\right)}{c}+\frac{\sum_{i=1}^{v} C_{L i}}{c}
\end{aligned}
$$

where, $\psi(z)=\phi(z)-z[1-\Phi(z)], \psi\left(z_{i 1}\right)=\mathrm{f}[\phi(\mathrm{z}), \Phi(\mathrm{z})]$

The total cost function is optimized subjected constraints of total shipments, shipment quantity, lead time, crashing cost.

\section{Iterative analysis used in CI-LT}

step 1: set $n_{i}=1$,

step 2: set $n_{i+1}=1$,

step 3: find $J T E C^{*}\left(\mathrm{c}, \mathrm{n}_{\mathrm{i}}, \mathrm{L}_{\mathrm{i}}, \mathrm{z}\right)$

step 4: $n_{1}=n_{1}+1$ and $n_{2}=n_{2}+1$ repeat the iteration till the joint total expected cost is minimum with correspond to all the constraints.

\section{ILLUSTRAIVE EXAMPLES}

The input data used here is refer to Ben-Daya and Raouf [11], Braglia and Zavanella [4], Ouyang et al.[12], Srinivas and Rao $[7,8,9,10] \mathrm{hv}=4 /$ unit/year, hbi=5/unit/year, $D_{1,2 \ldots 10}=$ $1000,1300,800,1000,1500,600,1200,1500,1000,800$ units/year, $\left(p / D_{i}\right)$ ratio $=3.2, \sigma_{1,2, \ldots .10}$ $=44.72,50,35.7,30,30,20,30,30,30,20, A_{v}=400 /$ setup, $A_{b i}=25 /$ order, $\pi=50 /$ unit. The lead time components are $\mathrm{L}_{\mathrm{i}(\mathrm{i}=0,1,2,3)}=14,10.5,7,5.25$ and its corresponding crashing cost are $\mathrm{C}_{(\mathrm{L}=0,1,2,3)}=0,1.4,5.6,14.35$.

The results show that with more buyers in the supply chain echelon the total cost savings are increased for single vendor - multi buyer (through Figures 1-7). The controllable lead time component is reduced up to minimum lead time, i.e., third lead time component. Whereas in case of single vendor - single buyer, the controllable lead time component is reduced up to second lead time component [Srinivas and Rao, 10]. 


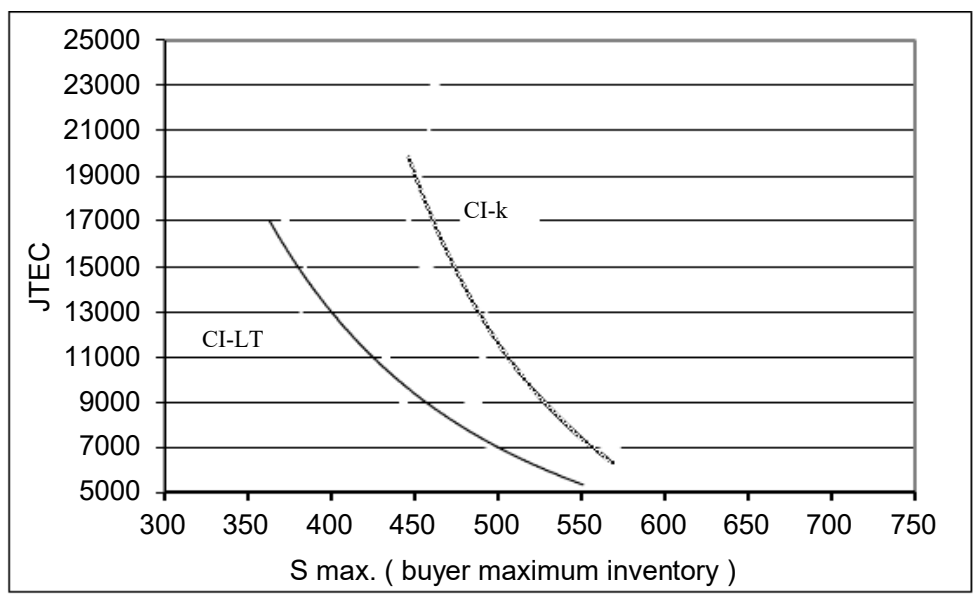

Figure 1 JTEC variation in CI-k and CI-LT

The total expected cost would be less in CI-LT model when compare to CI-k model (Figure 1) and it reduces while increasing buyer maximum stock, it shows that for the given strategy can make more customer choice availability. In CSP-LT model, the JTEC is sensitive to lead time components and crashing cost reduction components. It is in the interest of vendor and buyer for choosing the structure of lead time reduction and its corresponding crashing cost components as well as its lead time components.

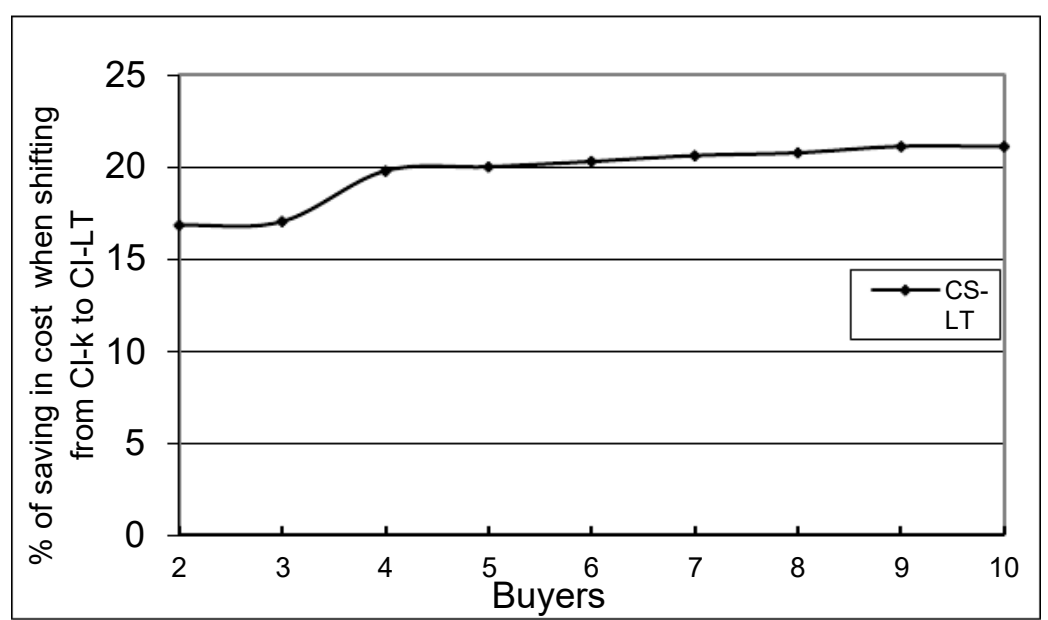

Figure 2 Percentage of saving in cost while moving from CI-k to CI-LT

Whenever the CI-k strategy shifted to CI-LT depending on the requiarement the Figure 2 shows the benefits that would be obtained. In these two models the maximum buyer stock varies closely but the minimum buyer inventory will have approximately 40 to $50 \%$ difference which continues with increase in buyer size (Fig.3), whereas the vendor inventory will have more in CI-k model compare to CI-LT model (Fig.4) and difference also have impact on customer demand fulfilment. 
Strategies of Delay Delivery and Controllable Lead Time to Optimize the Total Cost in Supply Chain Consignment Inventory

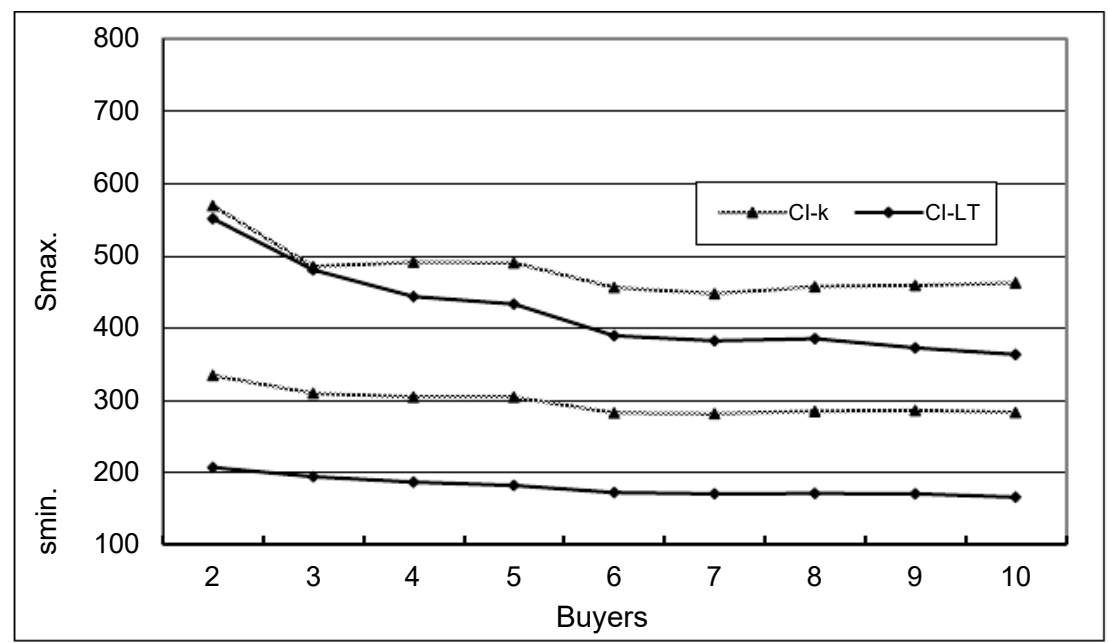

Figure 3 Maximum and Minimum stock levels

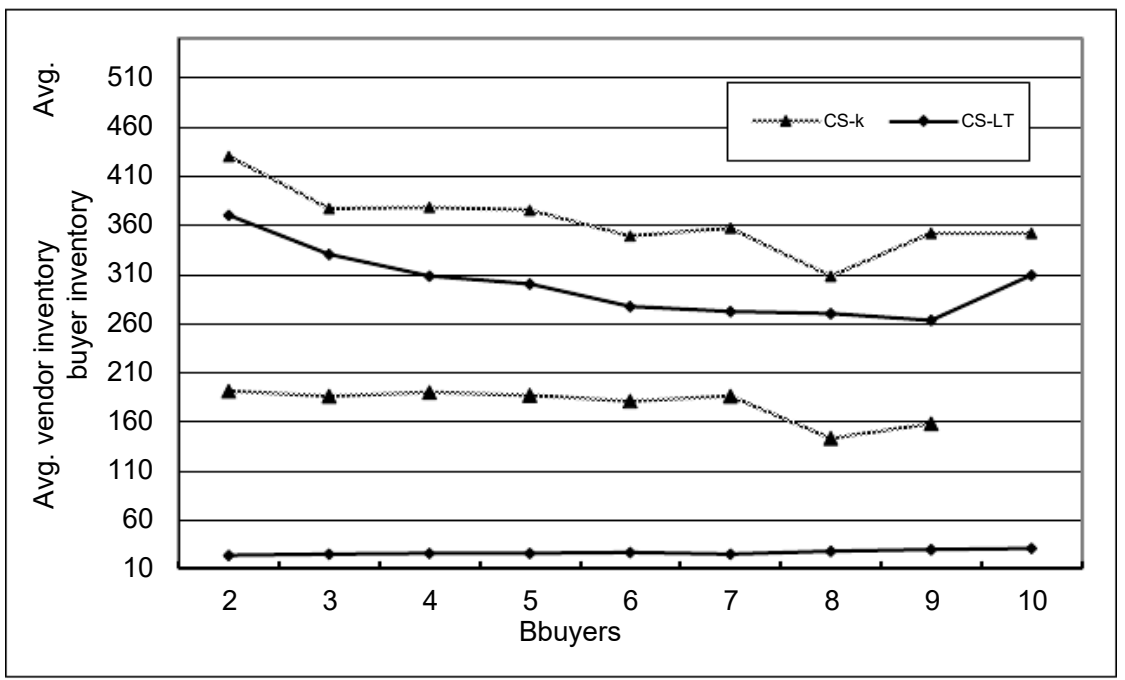

Figure 4 Variation of average vendor and buyer inventories while increasing buyers

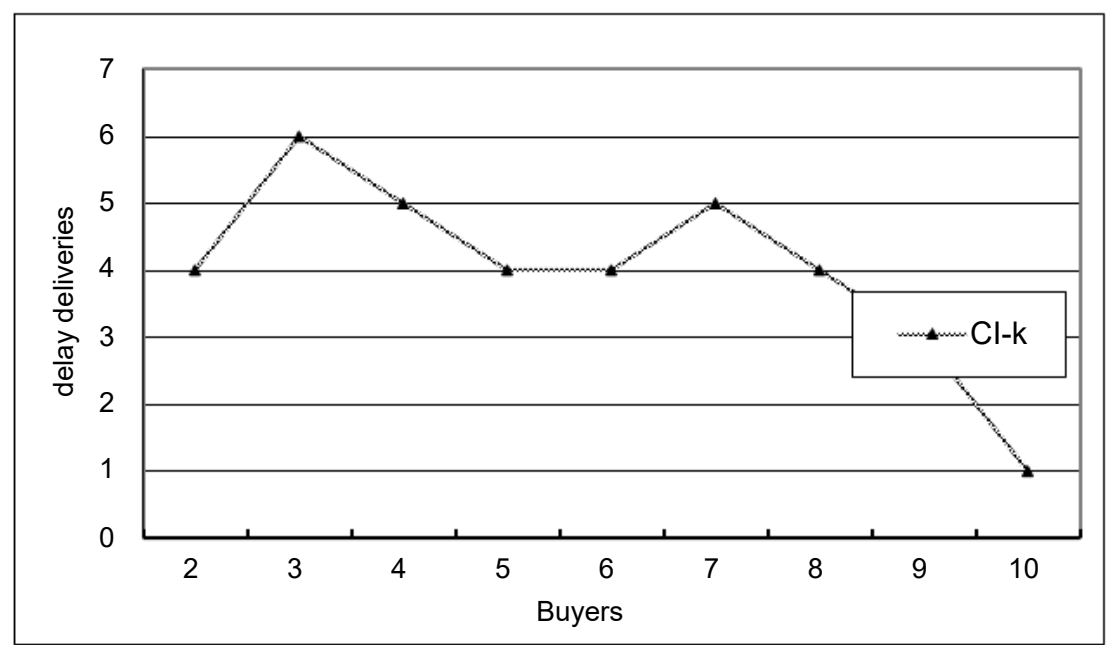

Figure 5 Delay deliveries in CI-k model

In delay delivery model, the deliveries shall reduce while increasing the buyer in the echelons (Fig.5), and hence significantly reduces the average buyer inventory with five eight buyer and further with increase in buyers. Hower the shipments in CI-k model increases and 
where as in CI-LT model the shipments stabilizes from buyer 6 onwards (Fig.6). It is due to the stabilizaiton of buyer max. and min. stock.

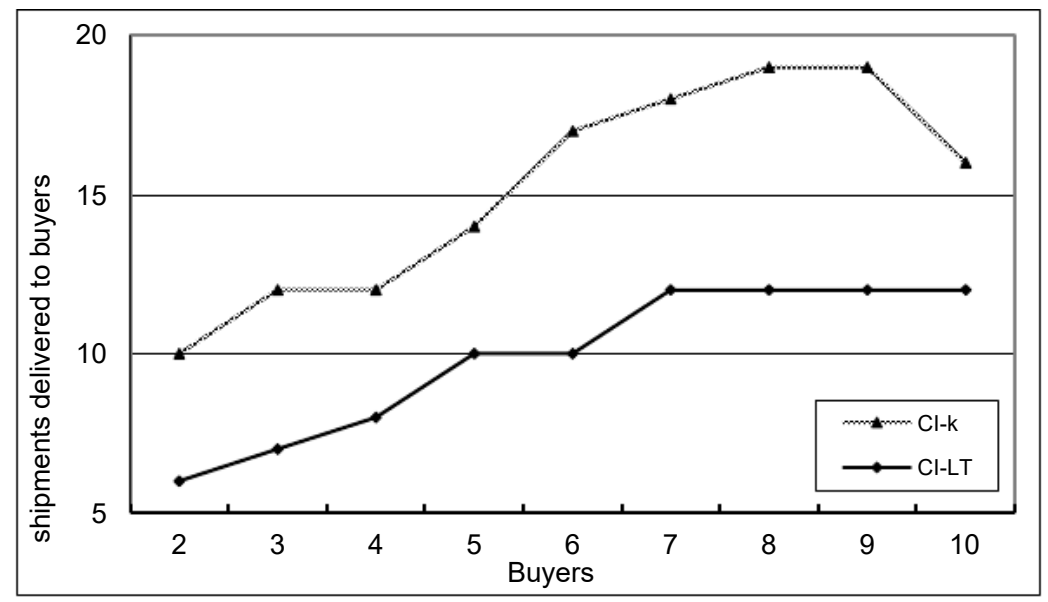

Figure 6 Number of shipment delivered transported from vendor to buyers

The Fig.7 depicts clearly that the shortage quantity is more in delay delivery model compare to controllable lead time and also a little variation would take place while increasing buyer size.

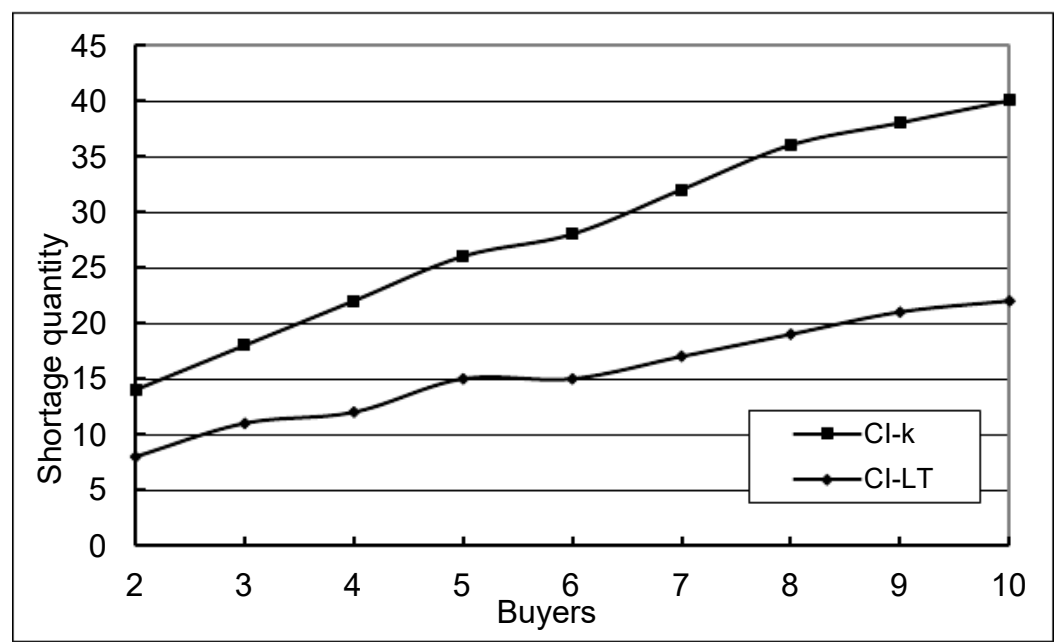

Figure 7 Effect of shortage quantity while increasing buyers

The curved line called efficient frontier shown in Fig.8 is generated by iteratively that minimizes the supply chain cost on the maximal $\mathrm{p} / \mathrm{D}$ ratio. The point ' $\mathrm{A}$ ' corresponds with a $\mathrm{p} / \mathrm{D}$ ratio of 3.2 at which lowest JTEC cost occurs for all consignment inventory models with stabilization.

If any supply chain strategy on the efficient frontier is undominated in the sense that there is no strategy exists which is at least as good with respect to JTEC. Moreover, it is found from the research articles of $[3,4,12,13,14,15]$ that they had considered production to demand ratio as 3.2 , but they could not mention the reason for choosing such value. In this paper the author has explained in detail regarding this capacity constraint $\mathrm{p} / \mathrm{D}$ ratio and its influence on total cost. At $\mathrm{p} / \mathrm{D}$ ratio 3.2, the JTEC getting steady state (Fig. 8). 


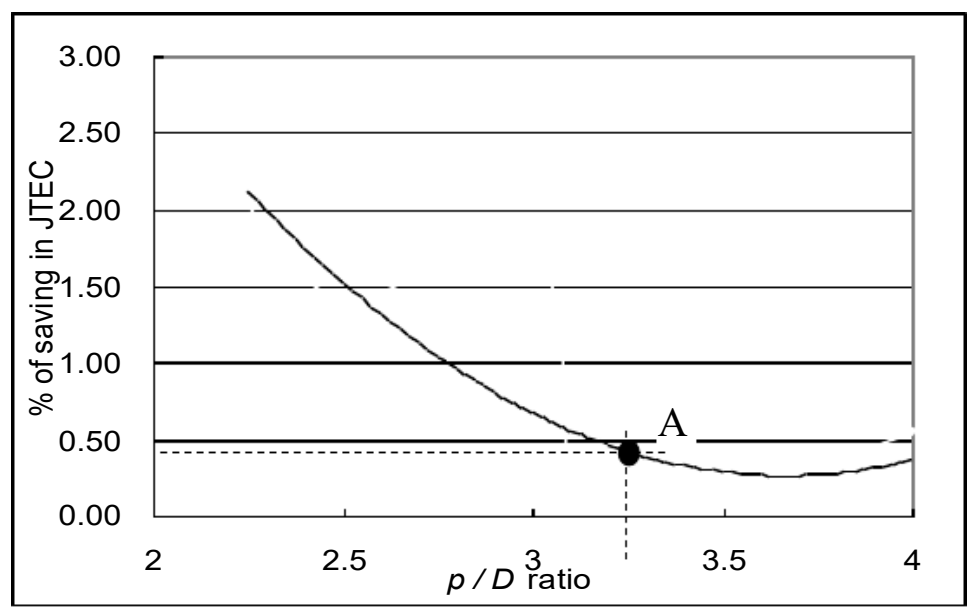

Figure 8 Efficient frontier effect of $\mathrm{p} / \mathrm{D}$ ratio on the percentage of savings

\section{CONCLUSIONS}

This article is focused on the development and analysis of consignment inventory of supply chain to minimize joint total costs of vendor and buyers in stochastic environment. The consignment inventory management policy with controllable lead time has proven to be most suitable for facing new Supply Chain challenges with stochastic demand for single vendormulti buyer. The developed models are not only make tradeoff but will also enable decision makers to deal with erratic judgments thoroughly. Hence concluded that CI-LT model is preferable when uncertainty in customer demand and lead time is more and when uncertainty in demand and lead time is less CI-IS- $\mathrm{k}^{1}$ model is preferable.

The total cost of controllable lead time model depends on lead time components and crashing cost components. The fixation of production to demand ratio is found to be crucial and is very sensitive to total costs apart from other variables. An extensive analysis has been made in this case and finally fixed at $\mathrm{p} / \mathrm{D}$ ratio of 3.2. The proposed model gives cost savings of approximately $9 \%$ compare to [3]. It is observed that $\%$ of cost savings increases as number of buyers increases. The CI-LT strategy could be best suitable for low or mid-price items and when the demand is stochastic in nature.

\section{REFERENCES}

[1] Houlihan, J. B, "International supply chain management", Int. J of Physical Distribution and Materials Management, 1985, vol.15, pp: 22-38.

[2] Simchi-Levi, D., Kaminsky, P., and Simchi-Levi, E.” Designing and Managing the Supply Chain: Concepts, Strategies, and Case Studies", 2000, McGraw-Hill, New York.

[3] Valentini, G. and Zavanella, L. E.,'The consignment stock of inventories: industrial case and performance analysis", Int J Prod Econ, 2003, vol.81-82, pp.215-224.

[4] Braglia, M. and Zavanella, L.E, "Modeling an industrial for inventory management in Supply Chains: the Consignment Stock case", Int J Prod Res, 2003, vol.41, No.16, pp.37933808.

[5] Hill, Roger. M, "The single-vendor single-buyer integrated production-inventory model with a generalized policy”, Eur J Oper Res, 1997, vol.97, pp.493-499.

[6] Hill, Roger. M, "The optimal production and shipment policy for a single-vendor singlebuyer integrated production - inventory problem", Int J Prod Res 1999, vol.37, pp.24632475 . 
[7] Srinivas Ch, Rao CSP, "Consignment stock policy with controllable lead time for effective inventory management in

[8] supply chains”, Int J Manuf Technol Manag, 2007, vol.10(2/3) ,pp.161-176.

[9] C. Srinivas and C.S.P. Rao, "Optimisation of supply chains for single vendor-multi buyer consignment stock policy under controllable lead time using genetic algorithm", Int. J. Manufacturing Research, Vol. 2, No. 2, 2007, pp.243-262

[10] Ch. Srinivas, C.S.P. Rao and Y.V.Rao, “Consignment stock policy using genetic algorithm for effective inventory management in supply chains", Int. J. Services Operations and Informatics, Vol. 3, No. 2, 2008, pp.107-126

[11] Chidurala Srinivas and Rao, C.S.P, "Optimization of supply chains for single vendor - multi buyer consignment stock policy with genetic algorithm” Int J Adv Manuf Technol, 2010 vol.48, pp.407-420.

[12] Ben-Daya, M. and Raouf, A, "Inventory models involving lead time as a decision variable", J Ope Res Society, 1994, vol.45, pp.579-582.

[13] Ouyang LY, Wu KS, Ho CH, "Integrated vendor-buyer cooperative models with stochastic demand in controllable lead time", Int J Prod Econ, 2004, vol.92, No.3, pp:255-266. 